\title{
O Futuro do Brasil no Pós-Guerra Segundo a Revista Em Guarda (1941-1945)
}

The Brazil Future Of Post-War From Em Guarda Magazine (1941-1945)

\author{
Aline Vanessa Locastre* \\ alinelocastre@hotmail.com
}

RESUMO: Em meio às incertezas geradas por um conflito bélico, que no caso da Segunda Guerra Mundial mobilizou inúmeros países e recursos, colocando em cheque a hegemonia de algumas ricas nações no cenário internacional, no Brasil, além das inúmeras privações decorridas deste acontecimento, foi verificado um cenário otimista perante as vantagens que este estado de beligerância poderia trazer ao futuro econômico do país. A partir da análise da revista Em Guarda, publicação criada pelo Office of the Coordinator of the Inter-American Affairs, agência subordinada ao governo estadunidense e que possuía como objetivo estreitar as relações entre Estados Unidos e América Latina durante os anos de 1940 a 1946 no programa de Boa Vizinhança, foi possível perceber que o teor da propaganda fomentada por esta agência para alcançar os "corações e mentes" de seus leitores brasileiros estava assentada, principalmente, na difusão do American Way of Life e de promissoras promessas para o pós-guerra.

PalaVRAs-ChaVE: Política da Boa Vizinhança, Revista Em Guarda, Segunda Guerra Mundial.

ABSTRACT: Amidst the uncertainties generated by a military conflict, which in the case of World War II mobilized numerous countries and resources, putting in check the hegemony of some rich Nations on the international stage, in Brazil, in addition to the countless deprivations after this event, it was verified an optimistic scenario on the benefits that this state of belligerency could bring to the country's economic future. From the analysis of the magazine "Em Guarda", publication created by the Office of the Coordinator of the Inter-American Affairs, subordinate to the American Government agency that had aimed to strengthen the relations between United States and Latin America during the years from 1940 to 1946 in the program of good-neighbor, it was possible to apprehend the purport of propaganda promoted by this agency to achieve the " hearts and minds " of its Brazilian readers seeking the diffusion of the American Way of Life and introducing promises for the post-war.

KEYWORDS: Good neighbor policy, Em Guarda magazine, World War II.

Política, econômica e militarmente, o Brasil está sendo, (...) um elemento de grande projeção no conjunto das forças vivas que ora traçam os grandiosos e sagrados destinos do Novo Mundo.

Revista Em Guarda, 1942.

A Segunda Guerra Mundial, maior conflito bélico que o mundo vivenciou no último século, com um saldo de milhões de mortos, cidades intensamente bombardeadas e o medo pela internacionalização do nazi- fascismo possibilitou ao Brasil, além da adesão à luta Aliada e o rompimento formal com a Alemanha e Itália, expectativas bastante positivas para um pósguerra favorável ao alavancar econômico do país.

\footnotetext{
* Doutorado em História pela Universidade Federal do Paraná (UFPR). Professora da Universidade Federal do Oeste da Bahia.
} 
Historicamente visto como inferior por diversos setores, inclusive governamentais dos Estados Unidos, o maior país da porção sul americana recebeu um tratamento especial no contexto beligerante da década de 1940. Com a criação de um órgão específico para tratar das relações com a América Latina e tentar minimizar as hostilidades geradas pelo intervencionismo estadunidense na região caribenha nas décadas anteriores, o herdeiro da Standart Oil (atual Esso) Nelson Rockefeller e o governo dos Estados Unidos, Franklin Roosevelt, gerenciaram programas para o estreitamento cultural e econômico da região. Era concretizava a Política da Boa Vizinhança, pensada anos antes pelo republicano Herbert Hoover. (SCHOULTZ, 2000, p. 325)

A revista Em Guarda, publicação estadunidense distribuída para toda a América Latina, foi largamente veiculada em vários países da região e por meio da análise de suas reportagens, que versavam sobre temas militares, em especial, auxilia-nos na percepção desta Política da Boa Vizinhança e das maneiras de como ela adentrou as fronteiras brasileiras. Esta revista, ainda pouco estudada no Brasil, oferece por meio de suas páginas a ampliação da gama de possibilidades para a problematização deste contexto. ${ }^{1}$

Dentre as inúmeras edições (quarenta e oito publicações ao longo de quatro anos) e seus quinze artigos em média por edição é possível aventurar no momento de incertezas que um contexto bélico é capaz de gerar. Levando em consideração a intenção de sua criação (disseminação da Política da Boa Vizinhança) a revista acaba se tornando ainda mais atrativa, uma vez que ela possibilita uma análise das relações que se procuravam estabelecer entre os Estados Unidos e os seus vizinhos continentais durante o conflito.

Assim, o objetivo principal deste artigo é o de mostrar o discurso da revista Em Guarda e das intenções da agência que a criou de fomentar no solo brasileiro a ideia de uma prosperidade inimaginável nos anos que sucederiam a Segunda Guerra Mundial, disseminado por reportagens bastante otimistas das potencialidades do país que mesmo parecendo ser essencial para o desfecho vitorioso do conflito, ainda era apresentado como inferior e atrasado.

\footnotetext{
${ }^{1}$ Poucos são os estudiosos no Brasil que se dedicam ao estudo da revista Em Guarda na análise específica de seu conteúdo. Nos deparamos com referências pontuais acerca da revista dentro do contexto da Política da Boa Vizinhança nas obras: (TOTA, 2000 e MOURA, 1984). Um dos estudos sistemáticos realizados sobre a Revista Em Guarda, salientando o panamericanismo presente em seu discurso foi a dissertação de mestrado: (SILVA, 2009)
} 


\section{O "Big Stick" não pertence aos "Bons Vizinhos"}

Nos anos que antecederam o período abordado neste artigo, mais especificamente a partir da Guerra de Secessão dos Estados Unidos, onde um exponencial crescimento do setor industrial acarretou em um efervescer econômico nas terras do "Tio Sam", a América Latina passou a ser vista com olhos diferentes, ou somente passou a ser realmente vista pelos policymakers estadunidenses. Provável mercado para seus produtos industrializados, que neste cenário já experimentavam os privilégios de uma larga escala de produção e com o temor de uma recolonização dessas ex-colônias por parte das antigas metrópoles europeias, os Estados Unidos optaram por uma política agressiva militarmente ${ }^{2}$, que punha em cheque a autodeterminação das recém libertas nações. Com um Big Stick em "mãos", Theodoro Roosevelt ameaçava aqueles que se mostrassem contrários ao seu imperialismo. ${ }^{3}$

Mas a política intervencionista continuou nas décadas posteriores (e assim permanece em nossos dias) acirrando ainda mais as rivalidades entre latino-americanos e estadunidenses. ${ }^{4}$ Lars Schoultz aponta que essas rivalidades perpassam as motivações políticas ou de interesse econômico na região. Elas também dizem respeito às tensões culturais existentes no continente, que segundo ele se baseiam em uma crença na inferioridade latino-americana e que norteou a forma como governantes da rica nação do Norte empreenderam as relações com seus vizinhos. Pensava-se em "civilizar" tais terras, pois ainda seriam frágeis em virtude das recentes emancipações; possuiria uma sociedade civil fragmentada, oportunidade ímpar para a instauração do caos devido à baixa densidade

\footnotetext{
${ }^{2}$ Em fins do século XIX, em especial nas regiões da América Central e o Caribe, o governo estadunidense interveio militarmente: "Cuba (1906-1909; 1917); Haiti (1915-1934); na República Dominicana (1916-1924); na Nicarágua (1912-1925; 1926-1933)." Sendo considerada a instalação de fuzileiros navais em Cuba para a independência perante a Espanha o marco inicial das intervenções estadunidenses na América Latina. (PELLEGRINO e PRADO, 2014, p. 119-120).

${ }^{3}$ Cunhada pelo presidente James Monroe, a Doutrina Monroe, datada ainda do século XIX previa que a América fosse dos americanos, ou seja, que a autodeterminação dos povos fosse respeitada caso houvesse uma tentativa de recolonização destas nações por parte de potências europeias (hipótese pouco provável, segundo o historiador Lars Shoultz). Mesmo sendo mais discurso do que prática, tal doutrina mostrava a tentativa de hegemonia estadunidense no continente, principalmente após as inúmeras intervenções militares no Caribe. Com a chegada do presidente Theodoro Roosevelt, tal discurso tornou-se menos brando quando da adoção do Corolário Roosevelt de 1904, que previa políticas mais ofensivas no caso de desrespeito a esta hegemonia. Surgiu o termo Big Stick para representar esta política que mantinha um discurso aprazível, mas admitindo a possibilidade de recorrer a um "porrete". (MOURA, 1991 e PECEQUILO, 2003).

${ }^{4}$ Procuramos referir neste trabalho aos cidadãos dos Estados Unidos como estadunidenses ao invés do termo comumente utilizado, norte-americano. Também optamos por ampliar as aplicações da palavra "americanos" para nos referirmos aos habitantes de todo o continente americano.
} 
demográfica; além da herança católica cristã, tida com péssimos olhos diante dos setores mais conservadores estadunidenses.

Um exemplo da propagação destes estereótipos foi percebido por João Feres Júnior em sua tese de Doutorado, que buscava entender as formas de apreensão do conceito de América Latina nos Estados Unidos. Constatou-se que comumente este conceito está relacionado a uma visão bastante preconceituosa destes povos, servindo para ressaltar a própria imagem estadunidense, uma vez que os últimos representariam o progresso e a modernidade.

Desde o século XIX era atribuído a esta porção do continente americano características inferiores, ao passo que, quando surgiu o termo latino-americano, rapidamente esta carga preconceituosa passou a compor seu significado. Observando vários verbetes que buscam a semântica da palavra Latino, é possível perceber uma intrínseca associação a aquilo que é irracional, movido por desejos carnais, com atitudes extravagantes e dissimulada, significado contido no Oxford English Dictionary. Nas entrelinhas, poder-se-ia também ler, segundo Feres Jr (2005):

Como podemos notar pelo texto das citações, os autores do dicionário economizaram na lista de adjetivos pejorativos da definição, pois ela poderia também incluir "ridiculamente pueril", "mulherengo", "malandro", "exibicionista", "fraco", "duplamente perigoso", "corporal" e "instável" (FERES JR, 2005, p. 18).

Outro estudo, bastante importante, relativo às visões lançadas sobre os latinoamericanos, foi realizado por Mary Anne Junqueira em uma análise da revista Seleções da Reader's Digest. Com um ideário de alargamento contínuo de suas fronteiras (Mito da Fronteira) na tentativa de "civilizar" os recônditos selvagens do mundo, os Estados Unidos buscaram difundir seu modo de sociedade aos povos localizados abaixo do Rio Grande. Nas matérias da revista, a partir dos anos de 1940, tais povos ainda eram tidos como "passivos, ignorantes, supersticiosos, vivendo de forma natural e instintiva, pois, conforme aquela ordem de ideias, o homem estava diretamente vinculado ao lugar primitivo" (JUNQUEIRA, 2000, p. 274). Na busca frenética do domínio da natureza pela técnica, latino-americanos pareciam seguir um caminho totalmente desviante, necessitando assim, da intervenção de uma nação modelar. 
Estes pensamentos minimizantes e a política direta ou indiretamente intervencionista não caíram por terra de uma hora para outra, mas durante o emergir da Segunda Guerra Mundial, elas tiveram que sair de cena para propiciar formas de agir menos intimidantes com vistas de manter sob o protetorado estadunidense as terras que, em um cenário de muitas privações, mostravam-se bastante promissoras. Ainda na década de 1920 formas de agir menos agressivas eram debatidas por Herbert Hoover ${ }^{5}$, então presidente republicano, mas com o cenário econômico devastador originado pelo Crash da bolsa de valores de Nova York em 1929 e as tentativas de reerguimento do país, os "bons vizinhos" não foram despertados no momento.

Para uma nação que desejava mercado para seus produtos industrializados e o desejo de manter sua soberania em uma região que não compartilhava valores nem objetivos em comum, fomentar hostilidades, não parecia um caminho ideal. Dentre as preocupações do novo presidente eleito em 1933, Franklin Delano Roosevelt, estava a necessidade de mudança nas relações com a América Latina e elas passaram a ser uma real possibilidade quando a iniciativa privada entra em cena.

Essa parceria intensificada entre empresários e a cúpula do governo Roosevelt foi possível com a instauração do New Deal, programa voltado para a recuperação econômica dos Estados Unidos após a crise de 1929. Inspirado na teoria de Keynes, este programa econômico buscava a intervenção do governo na tentativa de conter a crise de consumo, que o desemprego em larga escala gerou. Assim, a criação de obras públicas, como escolas, creches, estradas e hospitais foram financiados pelo estado com a intenção de inserir o trabalhador no mercado de consumo e solucionar, pelo menos em partes, a crise causada pela superprodução (MONTEIRO, 2014, p. 39).

Com a criação de leis que regulavam os valores imobiliários, Roosevelt conseguiu o apoio de alguns empresários que buscavam estabelecer seus mercados fora do país. Entre os nomes, Coca-cola, IBM, General Eletric, Pan Am, chama a atenção o apoio do grupo Rockefeller, representados a partir da Standart Oil e Chase National Bank. No alvorecer da

\footnotetext{
${ }^{5}$ Antes de tornar-se presidente da república, em seu posto como Secretário do Comércio dos Estados Unidos, Herbert Hoover alertava seus superiores da necessidade de modificação no tratamento com seus vizinhos latinoamericanos, para o bem de seus negócios na região. Atribui-se a Hoover a primeira utilização oficial do termo "bons vizinhos". (SCHOULTZ, 2000).
} 
Segunda Guerra Mundial, o herdeiro deste império, seria peça chave para a consolidação das relações interamericanas (MONTEIRO, 2014, p. 49).

Vice-presidente dos Estados Unidos, de 1974 a 1977; governador do Estado de Nova York de 1959 a 1973; Nelson Aldrich Rockefeller, bilionário, herdeiro de um verdadeiro império do petróleo ${ }^{6}$; nascido em uma família, que por iniciativa de seu pai, John Rockefeller Jr, foi marcada pela filantropia, foi apontado como um mecenas da arte pois, entre outras tantas funções, chegou a tesoureiro, administrador e presidente do Museu de Arte Moderna (MOMA) e fundador do antigo Museu de Arte Primitiva em Nova York.

Também pode ser incluído em sua lista de cargos o de ator proeminente, juntamente com o escritório que coordenou durante a Segunda Guerra Mundial, responsável pela implementação da conhecida "Política da Boa Vizinhança", que marcou as relações entre Estados Unidos e América Latina na década de 1940. Pelo sucesso deste programa, recebeu o convite do presidente Roosevelt para assumir a Vice Secretaria de Estado para as relações interamericanas em 1944.

O conhecimento sobre seus "vizinhos" provinha desde a década de 1930, quando o jovem Rockefeller começou a perceber que algo diferente deveria ser feito em relação ao tratamento desferido aos latino-americanos. Com a intenção de manter as filiais da Standart Oil além das fronteiras de seu país Nelson buscava conhecer melhor os povos que ali se inseriam, em uma tentativa de evitar as hostilidades geradas pelo cenário político cada vez mais propenso a regimes nacionalistas e hostis à hegemonia estrangeira (COLBY e DENNETT, 1998, p. 112 e 113).

Um dos exemplos mais contundentes da forma como este herdeiro buscava unir lucros com formas diferentes de agir, foi nas várias visitas que este fazia aos funcionários de suas empresas, localizadas na América Central e do Sul. Na visita de 1937 à Venezuela deparou-se com as cercas altas de arame fardado que envolvia o conglomerado da Standart Oil, separando os funcionários e suas famílias do restante da população local. O jovem bilionário ficou estarrecido com a cena, uma vez que a empresa se assemelhava a uma

\footnotetext{
6John Davison Rockefeller, formado na religião Batista, via o enriquecimento como obra de Deus. Assim, de vendedor de perus no Estado de Nova York em meados do século XIX, tornou-se o fundador da Standart Oil, que por muitos anos monopolizou a venda e distribuição dos derivados do petróleo, tais como a querosene e a gasolina. Foi considerado pelo Guinness Book como o homem mais rico do mundo. (TOTA, 2014).
} 
fortaleza. O isolamento com a cultura local mostrava nitidamente que a intenção deles era apenas o lucro, o que ampliava cada vez mais as distâncias entre tais povos (COLBY e DENNETT, 1998, p. 112 e 113).

Nelson, que desde tempos passados havia se arriscado a aprender um pouco de espanhol, ficou perplexo ao saber que ao menos a língua local seus empregados estadunidenses falavam. Segundo eles mesmo admitiram em conversa com seu chefe, não viam a necessidade de se aprender a língua de seus subordinados uma vez que ela não era utilizada em suas relações cotidianas de trabalho. Como não poderia ser? Se a empresa estava situada na Venezuela? Assim, algo deveria ser modificado, do contrário, seus negócios estariam condenados neste ambiente em que as aspirações nacionalistas cresciam dia a dia (COLBY e DENNETT, 1998, p. 112 e 113).

Nascia, após esta viagem, um desejo em Rockefeller de incentivar um modo diferente de se relacionar com seus vizinhos com vistas a combater relações hostis cada vez possíveis entre tais nações. Iniciaram planos para adentrar na América Latina de forma mais branda, menos impositiva, porém, não menos intervencionista (Soft Power). Das reuniões que passou a fazer em seu apartamento na Quinta Avenida, em Nova York, com o intuito de discutir estes planos de forma mais concreta, surgiu a oportunidade de levá-las ao presidente Roosevelt, que em alguns anos, o escolheria para gerenciar a Office for Coordination of Commercial and Cultural Relations between the Américas, crédito recebido por meio de seu histórico de contato e amplo conhecimento da latino-américa.

Um ano depois, já em 1941, o nome desta agência foi alterado para Office of the Coordinator of the Inter-American Affairs (OCIAA), atestando o grande crescimento do prestígio e das funções as quais Nelson Rockefeller conduziria (TOTA, 2000, p.50). Esta agência trabalhou em diversos setores, priorizando todos os programas que estreitassem as relações entre americanos. Assim, desde programas de rádio, revistas, filmes educativos, financiamentos, programas de saúde, intercâmbio de professores, alunos para os Estados Unidos e de artistas de Hollywood para figurar com "seus vizinhos", o OCIAA mergulhou na América Latina de forma rápida e notadamente eficaz.

Gerenciada de seu país sede, esta agência contou com mais de 1100 funcionários durante a sua existência $(1940$ - 1946), sendo que deste total, 300 homens seletamente escolhidos para tais funções trabalharam diretamente em países da América Latina. Seguindo 
a filosofia apregoada por seu coordenador, os funcionários do OCIAA deveriam imergir na cultura ao qual estavam vivendo, priorizando a interação com as autoridades locais e o povo em geral.

Com o avanço nazista nos primeiros anos de guerra e a grande incidência de colônias japonesas, italianas e alemãs, principalmente no sul do Brasil ${ }^{7}$, o OCIAA também atuou como força de contenção de "nazistas". O foco era a busca, em especial daqueles que desempenhavam atividades na área de propaganda, de agentes ou simpatizantes dos governos totalitários europeus. Proibiu-se tudo o que pudesse ser entendido como propaganda Nazista, como filmes ou programas de rádio (CRAMER e PRUTSCH, 2006, p. 791).

O tema de "cooperação econômica" foi bastante salientado no discurso oficial da agência, salientando a ajuda que se prestariam "às economias doentes", abrindo portas para gerir inúmeros financiamentos, investindo nos setores de turismo, produtos e na expansão de seus mercados. Muitos homens de negócios latino-americanos, que possuíam grandes cargos no setor econômico, foram incorporados às atividades do OCIAA como forma de dotá-los de experiência para aplicar o aprendizado em seus países de origem (CRAMER e PRUTSCH, 2006, p. 792).

A maneira mais comum desta cooperação econômica foi o fornecimento de materiais estratégicos para os Estados Unidos em troca de financiamentos de indústrias de base, como ocorreu com a Usina de Volta Redonda e a Vale do Rio Doce no Brasil. Ao enviar matéria-prima necessária para a indústria bélica, pois a fragilidade econômica dessas nações não permitia outras formas de negociação, implicitamente sua posição de inferioridade ficava notória, restando a estes povos, aproveitar a Guerra para lançar bases sólidas em suas economias ainda bastante dependentes do capital e produtos industrializados estrangeiros.

Realmente existia uma discrepância enorme entre as economias americanas. Enquanto nos Estados Unidos a tecnologia industrial supria as demandas de sua sociedade, as repúblicas latino-americanas eram dependentes de produtos acabados. No que tange às importações, o Brasil carecia de milhares de artigos acabados do exterior, sendo eles:

\footnotetext{
${ }^{7}$ Segundo os relatórios oficiais produzidos pelo Office of the Coordination of the Inter-American Affairs, aproximadamente 1.500 .000 imigrantes dessas nacionalidades viviam no Brasil, número não agregava seus descendentes. In: Activities of the Coordinator of the Inter-American affairs. May, 1943. Library of Congress, LOC F2508 U582.
} 
petróleo, cimento, cabos para telégrafos, cinema, carvão, papel para o jornal, enfim, possuía um setor industrial modesto e bem longe de se tornar autossuficiente (McCANN, 1995). Tal dependência justifica a demasiada intenção de Getúlio Vargas durante seu governo de trazer indústrias de base para o crescimento dos demais setores de bens de consumo para seu país.

Em dados oficiais do OCIAA sobre o Brasil, em 1942 o país possuía um veículo motorizado para cada 237 habitantes. O consumo que atendia às necessidades básicas era privilégio de apenas $15 \%$ da população, que predominantemente morava no campo e não usufruía da mesma qualidade de vida que os residentes da zona urbana. Os dados mais atualizados deste relatório, que datavam de 1920, apontavam para $31 \%$ de uma população que possuía emprego remunerado e $70 \%$ de uma população analfabeta.

No gráfico abaixo, produzido de acordo os dados do IBGE, mostram que esta busca de Vargas pelo crescimento industrial do país, em um período de dez anos, foi sentido de maneira mais intensa na Metalurgia, couros, peles, produtos farmacêuticos, têxtil, vestuários, calçados e produtos alimentares. Grande parte destes setores era dependente do investimento em maquinários e de transformação de matérias-primas, que no caso do Brasil, o último sempre existiu em abundância.

\begin{tabular}{|c|c|c|}
\hline \multicolumn{3}{|c|}{ VALOR DA PRODUÇÃO INDUSTRIAL BRASILEIRA (Cr\$ 1000$)$} \\
\hline & 1939 & 1949 \\
\hline Metalúrgica. & 488562 & 4468989 \\
\hline Material elétrico e de comunicações.............. & 352888 & 763128 \\
\hline Couros e peles e produtos similares............ & 108763 & 626963 \\
\hline Produtos farmacêuticos & 175364 & 1335787 \\
\hline Téxtil..... & 1412628 & 9358541 \\
\hline Vestuário, calcados e artefatos de tecidos... & 310194 & 2034443 \\
\hline Produtos alimentares.... & 1511366 & 9780459 \\
\hline
\end{tabular}

Imagem 1: Produção industrial do Brasil de 1939 a 1949 (LOCASTRE, 2012)

Assim, o grande discurso do OCIAA foi o de proporcionar o desenvolvimento do setor industrial do Brasil (também de diferentes países da América Latina) a partir do investimento das potencialidades já existentes na região, a dizer, as riquezas de seu solo e subsolo. Percebemos esta proposta nos inúmeros documentos que a agência produziu nos anos que esteve em vigência nos relatórios produzidos por suas três divisões: Divisão Comercial e Financeira; Divisão de Comunicações e Divisão de Relações Culturais (TOTA, 2000, p 47 e 48). 
A justificativa provinda de sua Divisão de Comunicações (neste artigo, representada pela revista Em Guarda) era a da necessidade em se unir a América em torno de uma luta em comum: da luta contra o totalitarismo nazifascista. Assim, duas nuances poderiam ser verificadas nas reportagens do mensário: a do fortalecimento da ideia de uma unidade americana (o Pan-americanismo) e a de minimização do inimigo, criando uma relação dualizada entre os "valores" propagados pelos Aliados e pelos países do Eixo.

A primeira ideia pode ser vista nas duas imagens apresentadas abaixo, onde a cooperação entre as nações é salientada. A primeira imagem, contracapa de uma edição da revista Em Guarda do ano de 1942, mostra todas as repúblicas americanas, lado a lado, unidas, matando a serpente do mal (ideia fácil se ser assimilada, uma vez que no imaginário cristão a serpente personifica o mal, no livro do gênesis). Um elemento faz-se importante observar: os Estados Unidos aparecem no plano superior da imagem, levando-nos a perceber sua liderança nesta empreitada.

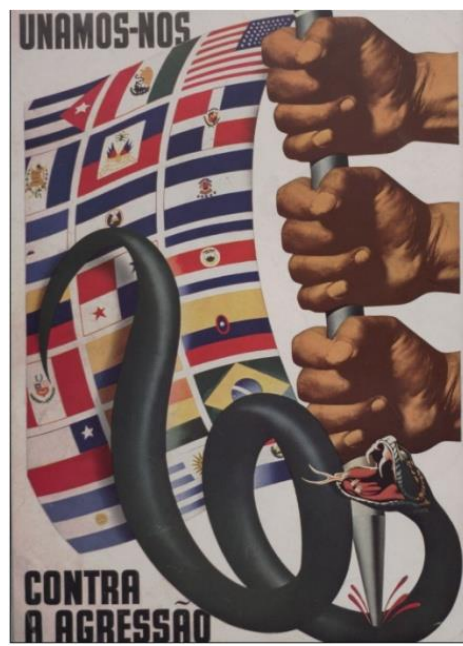

Imagem 2: Américas Unidas contra o Eixo Contracapa da revista Em Guarda (EM GUARDA, Ano 2, n. 4)

A outra imagem nos impulsiona a um pensamento similar ao anterior, pois seu apelo principal recai sobre a ideia de união americana. Na ilustração do periódico, todos os materiais utilizados para se construir as armas para o front de guerra viriam da América Latina. A pouca possibilidade de contribuição tecnológica ou mesmo bélica, seria suplantada pelo envio do material essencial para o desfecho do conflito. Caberia aos Estados Unidos a transformação deste por meio de sua tecnológica industrial. Rockefeller e o governo estadunidense promoveriam a melhor maneira de extração e transporte desses recursos. Em longo prazo, tais repúblicas poderiam gozar desta mesma capacidade industrial, bastava aceitar o apoio e colaborar com este esforço pan-americano. 
Percebe-se assim, que a posição de inferioridade latino-americana é mascarada com discursos mais suaves, didáticos e envolventes, mas não menos imperialistas. A possibilidade de se tirar proveito desses recursos caberia aos Estados Unidos, que pareciam não medir esforços ao garantir a paz e democracia no continente e no restante do mundo.

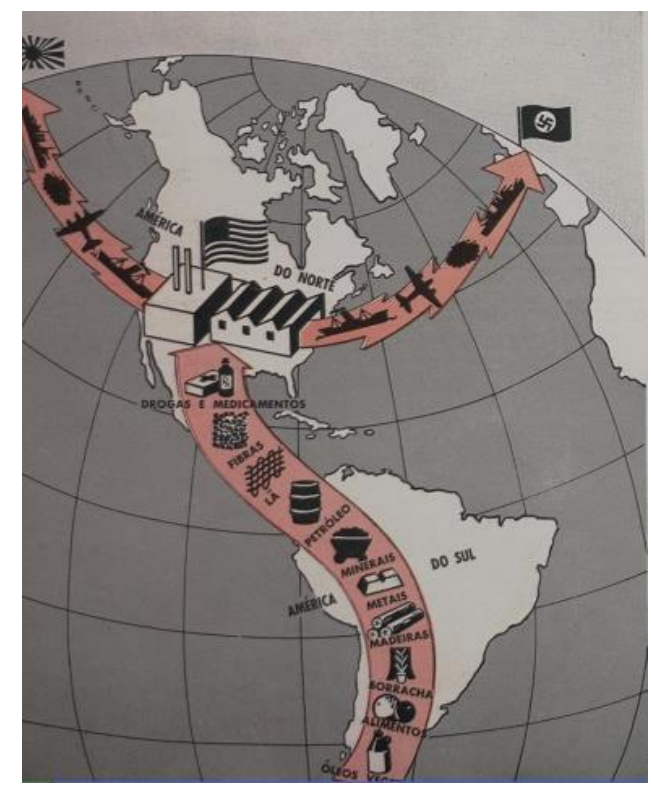

Imagem 3: Materiais estratégicos da América Latina (EM GUARDA, Ano 3, n.7, p. 6)

A outra nuance da propaganda do OCIAA demarca a atribuição ao inimigo dos males surgidos no mundo por conta das restrições instauradas à liberdade, representada pela democracia liberal e estadunidense. Na imagem que segue abaixo, esta relação maniqueísta, do bem e do mal, é exposta claramente por meio das imagens e legendas que a acompanha. O mundo estaria destinado a duas possibilidades: liberdade e escravidão. Neste mundo livre, privilegia-se a família, a liberdade de expressão e de crença religiosa. O nazismo traria a dor, o sofrimento e a ruptura com os dogmas religiosos.

Em uma guerra que aos poucos conclamava mais povos, um inimigo necessitava ser combatido: o nazifascismo. O futuro da liberdade parecia ceder a cada ofensiva perdida pelos Aliados no front de guerra. Os latino-americanos, distantes geograficamente do conflito, sentiam as privações deste conflito em seu cotidiano, abrandando as distancias que as milhas teimavam em conceder. Por meio da agência oficial do governo e liderada por Rockefeller estes povos passaram a se perceber como parte essencial desta luta, que requeria as potencialidades que ainda para eles poucos serviam, mas que eram mostradas pelos funcionários do OCIAA como peças de grande valor neste tabuleiro. 


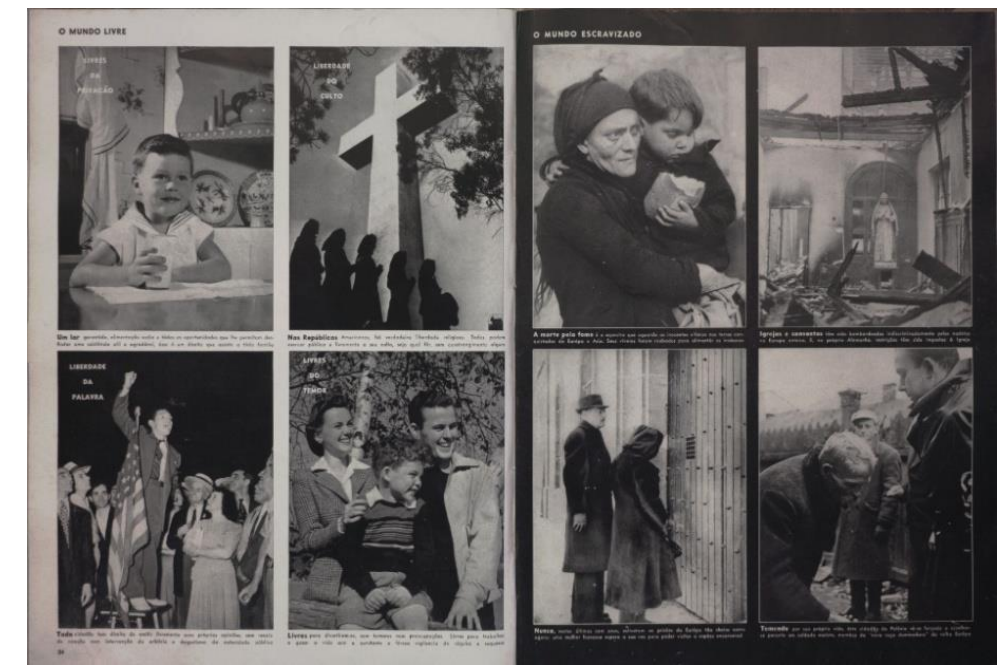

Mundo livre. Mundo escravizado (EM GUARDA, Ano 1, n. 8 p. 24 e 25)

A revista Em Guarda e as projeções de Brasil para o pós-guerra

Publicação mensal do Office of the Coordinator of the Inter-American Affairs, a revista Em Guarda foi folheada por inúmeros latino-americanos durante a Segunda Guerra Mundial. Isso foi possível, pois este material possuiu uma distribuição significativa para a época, que estava acostumada com as famosas publicações do Cruzeiro, Seleções da Reader's Digest ou com a famosa Life Magazine. Chegou de modo tímido, com uma tiragem de 8.000 revistas mensais no início da guerra, mas devido ao seu sucesso perante os leitores, em fins de guerra adquiriu um número expressivo de 550.000 para cada edição, de versões que eram traduzidas para o Espanhol, Francês e Português (SADLIER, 2012).

Escrita e impressa em Nova York, era redistribuída para a América gratuitamente, possivelmente para ser vista pelo maior número de leitores, inclusive aqueles menos abastados. No entanto ela era entregue, em grande parte, em bibliotecas e universidades das grandes cidades do país o que acabava restringindo sua leitura. Supomos que tiveram acesso a ela, intelectuais, militares, políticos, estudantes e civis que possuíam interesse no assunto. Em algumas memórias de guerra, vez ou outra, a leitura da revista Em Guarda foi citada pelos ex-veteranos de guerra, ganhando ares de saudosismo.

Como ela foi criada em um contexto em que se pretendia disseminar a Política da Boa Vizinhança na América Latina, a própria história de seu nome já nos aponta as diretrizes que seu conteúdo traria. A proposta inicial era o nome: Em Marcha. Mas Cordell Hull, Secretário de Estado estadunidense, encarou como muito impositiva, podendo remeter a uma 
alusão diferente da qual seu país pretendia mostrar. Em Marcha dava uma conotação de ataque. Não seria uma boa ideia! (TOTA, 2000, p.56)

A proposta vencedora foi: Em Guarda - para defesa das Américas, que busca ressaltar o fato de uma luta indispensável para a manutenção da paz no mundo, ressaltando o caráter heroico dos Aliados, que estariam preparados caso fossem atacados seus valores e sociedade. E assim ela permaneceu por quatro anos levando informações do front de guerra para a casa de cidadãos dos confins americanos.

Cabe citar algumas características, tanto físicas como de conteúdo, que distinguiam essa publicação das demais revistas do período. À primeira vista logo notamos uma novidade: ela possui grandes dimensões: $25,5 \times 35 \mathrm{~cm}$, detalhe que chama bastante a atenção. Sua capa traz fotografias coloridas que sempre pertencem a personalidades importantes dos Estados Unidos, soldados desconhecidos que lutavam na Europa ou imponentes armamentos de guerra. Em seu interior, vemos muitas fotografias, que geralmente tomam grande espaço das páginas e de ótima resolução, dando uma impressão de veracidade àquilo que se busca transmitir (BURKE, 2004).

O conteúdo das reportagens aborda assuntos referentes ao conflito, destacando em especial as vitórias dos Estados Unidos e Inglaterra no solo europeu; os armamentos utilizados e a sua superioridade perante as armas nazistas; algumas reportagens, como citado anteriormente, objetivam a destituição do oponente, ressaltando as privações que os povos conquistados estavam experimentando. Salienta-se aspectos das repúblicas americanas (entre elas os Estados Unidos) como suas economias, política, indústria (ou a necessidade dela) e seus aspectos geográficos. Pouca ênfase recebe o povo ou sua cultura, o que caracterizava uma publicação bastante técnica e o pouco conhecimento dos redatores sobre tais países.

Nos levantamentos qualitativos e quantitativos realizados no periódico, onde se buscou o número de temáticas referentes às repúblicas latino-americanas, percebemos que em número de reportagens o Brasil possuiu bastante destaque, ficando à frente de todas as outras nações do continente. As grandes capitais: Rio de janeiro, São Paulo e Belo Horizonte receberam um espaço no mensário, obtendo grandes elogios dos redatores de Em Guarda, que as comparavam às grandes metrópoles estadunidenses. 
Getúlio Vargas, Salgado Filho, Mascarenhas de Morais e Eurico Dutra também receberam espaços na publicação, que enalteciam seu empenho ao povo brasileiro e eram responsabilizados pelos rumos de progresso que o Brasil estava trilhando. Em diversos trechos podemos ler intensos elogios a estes personagens, que ajudavam, em diferentes graus, das aproximações políticas de ambos os países: "Getúlio Vargas, figura preponderante no congraçamento dos povos do Novo Mundo. Sob sua liderança, o Brasil tem alcançado enorme progresso industrial" (EM GUARDA, ano1, n. 10, p. 11).

Este progresso, sempre evocado na revista e associado como conceito inerente da democracia, era atribuído ao Brasil em sua história recente. Após o incentivo de Getúlio Vargas pela industrialização do país, este futuro promissor mostrava-se possível. Tal modelo de progresso seria universal, um caminho pelo qual as sociedades passariam. Os Estados Unidos já haviam desbravado este percurso, povoando o oeste, alargando suas fronteiras, garantindo a liberdade para seus cidadãos e expandindo sua economia.

As promessas para o Brasil eram bastante positivas, cabendo, como primeiro passo uma efetiva adesão à luta Aliada e aos acordos econômicos oriundos deste processo. Foi possível perceber ao longo dos quatro anos de edição da revista Em Guarda uma ideia repetidamente apregoada, mesmo que não citada explicitamente, poderia ser entendida nas entrelinhas deste documento histórico como uma fórmula para o progresso:

\section{IMPLANTAÇÃO DE INDÚSTRIAS + INVESTIMENTO DO INTERIOR = MELHORIA DOS PADRÕES DE VIDA DOS BRASILEIROS.}

Sabendo como melhor aproveitar o momento de privações ao qual o mundo passava, que a cada dia mais eram necessárias matérias-primas para vencer o "inimigo" na Europa e que por conta das significativas demandas e restrições, os antigos fornecedores já não podiam ou não conseguiam suprir estes mercados, caberia aos países latino-americanos explorar seu rico solo e subsolo, extraindo dele aquilo que de mais valioso existia no momento e que poderia garantir-Ihes (principalmente ao Brasil) um futuro que até uma década atrás parecia inimaginável.

Sonhos possíveis: Implantação de indústrias e transformação do interior brasileiro.

O projeto já estava imaginado. O governo de Getúlio Vargas ainda na década de 1930, buscava suprir a necessidade do país por produtos básicos (como citado anteriormente) a fim 
de concretizar sua busca pela autonomia econômica que dependia naquele momento, quase que exclusivamente, das importações da Europa e dos Estados Unidos, em especial.

Sem petróleo, cabos para telégrafos ou mesmo produtos farmacêuticos, seria praticamente impossível introduzir de forma plena os projetos de crescimento brasileiro. Ele ficaria sempre à mercê de outras nações. O programa de Boa Vizinhança estadunidense possibilitou o empréstimo (que havia sido negado por alguns bancos estrangeiros) para a viabilidade de empreendimentos, como a Fábrica Nacional de Motores, a Companhia Siderúrgica Nacional (CSN) e a Usina de Volta Redonda8.

Acompanhado dos relatos sobre a implementação das indústrias, o auxilio estadunidense era sempre evocado nas matérias analisadas, ressaltando que sozinho o Brasil não seria capaz de concretizar seus planos de progresso. Na reportagem que explorava a Fábrica Nacional de Motores, a parceria Brasil - Estados Unidos rendeu o destaque principal, salientando que por intermédio de Salgado Filho, que havia visitado a terra de "Tio Sam" recentemente (meados de 1944$)^{9}$, a autorização para fabricação de motores da Wright Aeronautical Corporation em seu país estava liberada.

Depois de uma viagem de agenda bastante extensa, Salgado Filho assistiu a um treinamento do grupo de paraquedistas no Tennessee, visitou várias fábricas de aviões onde viu de perto seu funcionamento e doou durante sua visita ao presidente Roosevelt, cerca de 400.000 sacas de café para os soldados no front europeu. Tal doação foi relatada com grande euforia na revista: "As autoridades militares americanas tomaram imediatas providências para que fosse feita a remessa da apreciada dádiva aos soldados" (EM GUARDA, Ano 3, n. 1, p. 23)

A exaltação da figura de Salgado Filho e a importância de sua visita podem ser acrescidas da identificação de um discurso no mensário que ressalta em demasia o reconhecimento tecnológico e bélico dos Estados Unidos pelo governo brasileiro e da importância que as relações entre ambos os países passavam a ter neste cenário beligerante.

\footnotetext{
${ }^{8}$ Ao mesmo tempo em que o Brasil recebia empréstimos para a construção de indústrias de base, essenciais ao seu desenvolvimento industrial, o país cedia bases aéreas na cidade de Natal, para servir como ponte para reabastecimento de tropas na Europa, chegando a ser intitulado como Trampolim da Vitória, por ter sido a base para mais de 25.000 voos para a Europa, África e Extremo Oriente. (ALVES, 2002, p. 98)

${ }^{9}$ A visita teria sido um sucesso e a Política da Boa Vizinhança nunca teria estado tão fortalecido como naquele momento, segundo consta em carta de Paulo Germano Hasslocher endereçada ao presidente Getúlio Vargas em 23/06/1944. In: FGV, CPDOC, GV c 1944.06.23.
} 
Como prova do reconhecimento de seus relevantes serviços prestados a bem do esforço de guerra das Nações Unidas, o governo dos Estados Unidos conferiu-Ihe a medalha de Ordem de Mérito, a mais alta condecoração norteamericana destinada a estrangeiros ilustres (EM GUARDA, Ano 3, n. 1, p. 23)

A posição de inferioridade do Brasil fica bastante nítida quando lemos a sensação de vislumbre que o ministro da aeronáutica supostamente aparenta ao notar que muito teria que ser feito no tocante à tecnologia deste tipo. Porém, ao ser noticiada a parceria que concederia a fabricação de motores, antes importados, na FNM e da transferência de Miami para São Paulo de uma escola de mecânicos aéreos, as vias para o crescimento econômico estavam lançadas e seu sucesso parecia ser questão de tempo.

Ao mesmo tempo, na região de Minas Gerais, no Vale do Rio Doce, as iniciativas para o progresso estavam sendo implantadas de maneira rápida e eficaz. Ao introduzir nesta região, dita como inóspita e de difícil acesso a tecnologia, a exploração efetiva de seu subsolo refletiriam no progresso causado ao seu entorno. O grande destaque na reportagem do Ano 3 da revista Em Guarda diz respeito ao melhoramento desta região, oriunda da modernização das ferrovias e do porto de Vitória, de onde sairiam o minério de ferro utilizado no esforço de Guerra dos Aliados.

Na pequena cidade de Itabira, localizada nesta rica região, havia sido encontrada uma gigante reserva no topo da montanha margeante à cidade. A quantidade de óxido de ferro na rocha foi estimada em $68,3 \%$, um dos maiores teores dentre os já conhecidos, com aproximadamente 14 bilhões de toneladas do minério, segundo os redatores da revista. A riqueza desta "montanha de ferro" proporcionava expectativas ímpares para a região, que após o conflito veria um crescimento ainda maior.

(...) quando estiverem concluídas as obras da Vale do Rio Doce, os vários recursos do interior encontrarão rápida saída, por terra e por mar, para abastecer agora a indústria bélica dos aliados e, depois da guerra, as indústrias do mundo inteiro. (EM GUARDA, Ano 3, n. 7, p. 37)

A extração do minério de ferro requeria driblar alguns problemas, sendo eles, em especial, de saúde pública. Como exigir uma produção maior, se as condições sanitárias para os milhares de trabalhados que chegavam à região não eram adequadas? Houve assim, uma parceria que envolvia o governo brasileiro e o estadunidense em programas de saúde. Um destes programas voltou-se pela erradicação de doenças como a malária, a varíola e o tifo, 
levando enfermeiras a conscientizar as famílias durante as suas visitas, promovendo uma educação sanitária em regiões que careciam de saúde e de educação.

A filantropia dos Rockefeller, em especial no investimento no campo da saúde ${ }^{10}$, reflete-se neste programa de boa vizinhança. A criação de um hospital e de quatorze dispensários ao longo das estradas auxiliou no estabelecimento do Serviço Cooperativo Interamericano de Saúde e na sua busca pela erradicação de determinadas doenças na região do Vale do Rio Doce. A instrução de novas enfermeiras e a utilização da profilaxia serviu para serem projetadas casas mais altas e ruas com drenagem para evitar a proliferação de mosquitos (EM GUARDA, Ano 3, n. 7, p. 36)

Diante da realidade brasileira, que possuía extensos vazios territoriais ${ }^{11}$, bem como uma população marcada pelas carências sanitárias, tecnológicas, de infraestrutura e de educação, as reportagens trazidas pela revista Em Guarda em plena Segunda Guerra Mundial mostram-se bastante positivas, priorizando as transformações as quais o país estava experimentando, graças ao capital estadunidense e do contexto de precariedade por matérias-primas da época.

As imagens que ilustram o periódico servem para "comprovar" aquilo que se diz, em relação às transformações e às possibilidades de um futuro mais promissor. Em uma imagem da pedreira de Itabira contrasta com a figura humana, que intervém na área buscando o progresso oriundo de seu valioso óxido de ferro. Lugares inóspitos parecem existir apenas por uma questão de tempo, até se tornarem fervorosos centros urbanos no pós-guerra.

Outro produto, indispensável para a guerra e ainda pouco explorado durante a Segunda Guerra Mundial encontrava-se no coração da floresta amazônica: o látex. Sendo a borracha indispensável nesses novos tempos, ou como afirmava o periódico, “(..) sem a borracha, nenhum exército moderno pode se movimentar" (EM GUARDA, Ano 2, n. 7, p. 26), o Brasil poderia oferecer aos Aliados este precioso produto em troca de possibilidades infinitas para a região.

\footnotetext{
${ }^{10}$ A filantropia dos Rockefeller, muitas vezes visava o investimento na saúde do trabalhador como maneira de aumentar a produtividade e os lucros de suas empresas. (COLBY e DENNETT, 1998).

${ }^{11}$ Os "vazios territoriais" estadunidenses foram conquistados com a expansão do Oeste, no qual dizimou indígenas e transformou o cenário natural com cidades e indústrias. Assim, todo local situado além das fronteiras desta nação que ainda se encontravam sem as intervenções da "civilização" foram tidas como necessitadas de dominação, única via considerada válida para o progresso. (JUNQUEIRA, 2000).
} 
Era pronunciado um novo alvorecer para a Amazônia, maior que aquele verificado no fim do século XIX. Embora as propagandas fossem bastante positivas, sabia-se que nesta gigante floresta, uma larga escala para a produção da borracha não seria tarefa fácil. Na frustrada tentativa de Henry Ford por produzir a árvore em grandes áreas desmatadas, as seringueiras sucumbiram facilmente devido ao ataque de pragas agrícolas. ${ }^{12}$

Mas as projeções para o futuro da região não se mostravam pessimistas nas reportagens que citavam este precioso produto brasileiro. Mesmo levando em consideração a contribuição das outras nações latino-americanas no esforço de guerra dos Aliados, como o petróleo extraído da Venezuela e Peru e da lã, que aquecia os soldados no intenso inverno europeu oriundas do Uruguai, o Brasil seria o fornecedor do mais decisivo deles: a borracha.

Depois desta guerra, quando os historiadores se entregarem ao registro da parte que desempenharam na luta os vários beligerantes, é quase certo que dentre as muitas contribuições para nossa vitória, feitas pelas nações Americanas, a que se refere à borracha estará dentre as de maior destaque (EM GUARDA, Ano 2, n. 7, p. 26).

Para uma efetiva exploração do látex, seria preciso trazer homens e mulheres dispostos a se embrenhar em uma floresta ainda virgem em diversos pontos a fim de possibilitar esperanças de levar a "civilidade" nestes grandes vazios territoriais. A falta de comunicação e as doenças da região eram até aquele momento os grandes empecilhos do progresso. No entanto, a partir da necessidade que a guerra fizera surgir e o apoio técnico e tecnológico estadunidense, tais barreiras estavam em vias de serem transpostas.

Com o fornecimento de quatro hidroaviões, o governo Roosevelt auxiliava no aceleramento postal dessas regiões até então isoladas e no fornecimento de medicamentos para equipes médicas que passaram a atuar no rio Amazonas e em seus afluentes ou em clínicas construídas em pontos estratégicos. Também se buscava combater o mosquito da Malária, doença que dizimava grande parte dos trabalhadores que se aventuravam nos recônditos amazônicos (EM GUARDA, Ano 2, n. 7, p. 26)

Tais sertanejos trariam em suas bagagens grandes expectativas, se por acaso eles lessem na revista Em Guarda as promessas para seu futuro. O foco do discurso priorizava a

\footnotetext{
${ }^{12} \mathrm{Na}$ tentativa de suprir as demandas de borracha nas indústrias de Henry Ford nos Estados Unidos, foi construída uma cidade em meio a Amazônia, chamada Fordlândia, que além de procurar extrair o látex em larga escala, tinha também o objetivo de levar o progresso para a região, que ainda não havia vivenciado o verdadeiro modelo civilizacional. (GRANDIN, 2010)
} 
melhoria das regiões ou cidades, como João Pessoa, Boca do Acre e Porto Velho, que passariam de "simples denominações cartográficas para centros nervosos na construção dinâmica de um novo grande império do interior" (EM GUARDA, Ano 2, n. 7, p. 28).

Em muitos trechos podemos ler sobre as relações entre o crescimento do interior brasileiro e a qualidade de vida dos desbravadores de seus confins. A possibilidade de permanecer em sua própria região ou mesmo, de se aventurar a terras pouco procuradas para enriquecer e construir significativa renda, seria viável a partir da exploração do látex. Um sonho era disseminado pelo OCIAA, o de um futuro sem grandes preocupações e de uma vida farta pouco possível para uma grande parte da população do Brasil na década de 1940.

Promessas ainda mais contundentes chegaram durante a construção da siderúrgica de Volta Redonda. Primeiros passos para a autonomia brasileira, esta usina seria um grande marco na história, segundo afirmações do próprio Vargas, ao viabilizar a transformação do minério de ferro e do carvão em aço, essencial para o desenvolvimento do país. Ainda segundo o presidente, "Volta Redonda será um marco da civilização brasileira, um exemplo tão convincente que afastará todas as dúvidas e apreensões acerca de seu futuro".

Além de citar o chefe do executivo brasileiro como o grande responsável pela construção da usina, que possibilitaria o aumento da industrialização e consumo no país, os Estados Unidos foram citados como os grandes colaboradores deste projeto, por meio do financiamento de quarenta e cinco milhões de dólares cedidos pelo Banco de Importação e Exportação de Washington (Ex-Im Bank) para uma amortização em 10 anos. Juntamente com o envio de técnicos este dinheiro serviria para a compra de maquinários e equipamentos que colocaria o grande sonho de Vargas nas vias reais de concretização. Era citado no mensário que o grande objetivo do governo Roosevelt era o de proporcionar ao Brasil a real condição de auxiliar na defesa do hemisfério ocidental (EM GUARDA, Ano 3, n. 3, p. 24).

Como o aumento das indústrias acarretaria no incremento de vida daqueles que direta ou indiretamente se relacionava a ela, citar estas melhorias passava a ser uma constante na publicação. Dessa maneira, a Vila operária de Santa Cecília seria um verdadeiro marco na forma como os funcionários desta empresa viveriam em seus momentos de lazer e descanso. Para sua devida instauração, seus trabalhadores deveriam gozar de boas instalações que lhes proporcionassem uma vida mais confortável. Na vila, as casas seriam todas de alvenaria, por volta de 1600, dividindo espaço com igreja, cinema, hospital, hotéis e escolas, 
suficiente para abrigar cerca de 5000 operários e assegurar a estes um futuro digno, com conforto e bem estar (EM GUARDA, Ano 3, n. 3, p. 24).

Porém, como garantir que a criação de indústrias e investimento nos vazios populacionais conduziria a um futuro sem precedentes em um país que ainda dependia em massa das importações estrangeiras? Existiriam fórmulas para o progresso em um cenário bélico ou quem seria este exemplo de progresso capaz de influenciar a economia e o futuro brasileiro?

Por ser um discurso oriundo de uma mídia específica, surgida em um contexto ímpar e por um governo que buscava parcerias em uma vizinhança um tanto quanto hostil às intervenções estadunidenses, tais perguntas parecem retóricas. O grande modelo de progresso publicado na revista Em Guarda seria a grande nação do norte, os Estados Unidos da América e os preceitos que este país defendia: a democracia, o capitalismo e a liberdade.

Ao analisar o teor das reportagens na revista Em Guarda, que em geral citavam os Estados Unidos como exemplo de economia, de sociedade, política e potência militar, foi possível estabelecer alguns paralelos com o tipo de discurso que era veiculado sobre os países da América Latina. Enquanto percebemos que a História sempre é utilizada para legitimar um passado glorioso aos Estados Unidos, o presente e o futuro caracterizam o conteúdo das reportagens destinadas à América Latina. Uma das justificativas para isso foi o desconhecimento que os funcionários da OCIAA tinham da história da região, mesmo sendo estimulados a superar tal problema.

Recorre-se a uma História ufanista, que descaracteriza os povos indígenas enquanto dotados de cultura, exaltando o feito que o homem "branco" realizara no país, com vistas de transformá-lo. Ao citar os Montes Rochosos no oeste estadunidense, por exemplo, aludemaos missionários espanhóis franciscanos como disseminadores das primeiras sementes da civilização, em uma terra "quase completamente inculta e desabitada"(EM GUARDA, Ano 3, n. 6, p. 10).

O desenvolvimento da região, que apesar de ser pouco povoada (menos de um habitante por quilômetro quadrado), ao focar na exploração do cobre e chumbo, na pecuária (possível pelos vastíssimos campos e encostas de montanhas)e nas jazidas de petróleo, propiciou o estabelecimento de uma população significava, a partir da construção da primeira 
estrada de ferro datada de 1869. O homem dominou a natureza "hostil" e a partir deste feito a "civilização" foi possível.

Muitas são as fotografias que ilustram as reportagens, servindo para comprovar aquilo que se procura enfatizar no texto. Ao apresentar uma localidade que pouco poderia ser explorada principalmente pelo perfil hostil de seu relevo e vegetação, ao intervir racionalmente neste espaço foi possível tirar proveio de seus potenciais naturais para seu progresso e da nação em geral.

Tão abrangente era este desenvolvimento, que ele não estava restrito a uma intervenção puramente econômica, de suas potencialidades, mas ocorria com o usufruto de todos os requisitos para o seu efetivo progresso. Serviço postal, jornais, programas de rádio, universidades, cinemas, teatros, tudo chegava rapidamente nesta inóspita localidade e sem tais serviços o prosperidade seria impensada.

E assim, o escritório de relações interamericanas veiculava sua propaganda implícita por meio de seu mensário mais conhecido nas Américas. Ao lado de uma produção intensa que visava difundir o American Way of Life por meio de filmes, desenhos animados ou mesmo produtos acabados, percebemos que na Política da Boa Vizinhança houve concomitantemente uma propaganda que buscava promover expectativas nas repúblicas aliadas aos Estados Unidos. Ao Brasil caberia a melhor posição: ser uma potência na porção sul do continente americano.

Palavras finais

Podemos perceber, ao fim deste breve artigo, que uma mesma história parecia se repetir na propaganda veiculada pela Revista Em Guarda, no que se refere às etapas de modernização vivenciadas pelas diferentes sociedades, porém, em etapas distintas para cada porção do continente americano. Enquanto a parte norte, mais especificamente os Estados Unidos da América, já gozavam dos benefícios que a modernidade lhes trouxera, os países latino americanos ainda engatinhavam nesta busca pelo desenvolvimento econômico. 0 caminho seria o mesmo: dominar a natureza -> investir em indústrias do interior -> colher os frutos do desenvolvimento.

O Brasil, nosso foco de estudos, mostrava-se como um bom aprendiz quando aceitou o auxílio econômico e técnico estadunidense para transformar as riquezas escondidas em seus 
vastos e distantes "vazios territoriais" no combustível para o seu crescimento. As promessas eram as mais auspiciosas, dignas de uma nação que poderia, a partir da Segunda Guerra Mundial, se projetar como potência na porção sul do continente americano.

Esta nuance da Política da Boa Vizinhança agrega aos estudos do tema que sublinham a venda do American Way of Life, deste modo de vida americano, sinalizando que a propaganda não visava apenas a "venda" dos valores e sociedade estadunidense. Uma das maneiras que os funcionários do OCIAA utilizaram para propagar esta cooptação de nações o esforço de guerra buscou salientar os benefícios que latino-americanos teriam se sua adesão aos Aliados fosse definitivamente firmada. O caminho para o progresso estava claro, bastava segui-lo. Este seria o preço da aliança firmada entre americanos contra os "inimigos" do Eixo: um futuro sem precedentes no pós-guerra, com o eterno agradecimento com aqueles que os ensinaram como "chegar lá".

\section{REFERÊNCIAS BIBLIOGRÁFICAS E FONTES}

ACTIVITES of the Coordinator of the Inter-American Affairs. May, 1943. Library of Congress, LOC F2508 U582.

ALVES, Vagner Camilo. O Brasil e a Segunda Guerra Mundial. História de um envolvimento forçado. Rio de Janeiro : Editora da PUC, 2002.

BURKE, Peter. Testemunha Ocular - História e Imagem. Bauru, SP: EDUSC. 2004.

COLBY, Gerard; DENNETT, Charlotte. Seja Feita a Vossa Vontade - A conquista da Amazônia: Nelson Rockefeller e o Evangelismo a Idade do Petróleo. Tradução de Jamari França. Rio de Janeiro: Record, 1998.

CRAMER, Gisela; PRUTSCH, Ursula. Nelson A. Rockefeller's Office of Inter-American Affairs (19401946) and Record Group 229. Hispanic American Historical Review, Duke University Press, November, 2006.

FERES JR. João. O conceito de Latin America nos Estados Unidos. Bauru, SP: EDUSC, 2005.

FGV, CPDOC. Carta de Paulo Germano Hasslocher ao presidente Getúlio Vargas. GV c 1944.06.23.

GRANDIN, Greg. Fordlândia: ascensão e queda da cidade esquecida de Henry Ford na selva. Trad. Nivaldo Montingelli Jr. Rio de Janeiro: Rocco, 2010.

JUNQUEIRA, Mary Anne. Ao sul do Rio Grande - imaginando a América Latina em Seleções: oeste, wilderness e fronteira (1942-1970). Bragança Paulista: EDUSF, 2000.

LOCASTRE, Aline. Projeção do Brasil para o pós-guerra: A Boa Vizinhança Estadunidense no Brasil segundo a revista Em Guarda (1941 - 1945). Dissertação de Mestrado. Universidade Estadual de Londrina (UEL), Departamento de Pós Graduação em História Social, 2012. 
McCANN, Frank. Aliança Brasil-Estados Unidos (1937-1945). Rio de Janeiro: Biblioteca do Exército Editora, 1995.

MONTEIRO, Erica G Daniel. Quando a Guerra é um negócio: F. D Roosevelt, Iniciativa privada e relações interamericanas durante a II Guerra Mundial. Curitiba: Editora Prismas, 2014.

MOURA, Gerson. Estados Unidos e América Latina. 2a ed. São Paulo: Contexto, 1991.

Sucessos e llusões - Relações Internacionais do Brasil durante e após a 2ª G. M.. Rio de Janeiro: Fundação Getúlio Vargas, 1991.

Tio Sam chega ao Brasil. São Paulo, Brasiliense, 1984.

PECEQUILO, Cristina Soreanu. A política externa dos Estados Unidos: Continuidade ou mudança? Porto Alegre: Ed. da UFRGS, 2003.

PELLEGRINO, Gabriela; PRADO, Maria Lígia. História da América Latina. São Paulo: Contexto, 2014.

Revista EM GUARDA. Nova York: Office of the Coordinator of the Inter-American Affairs. Ano 1 a 4.

SADLIER, Darlene J. Good Neighbor Cultural Diplomacy in World War II. Austin: University of Texas Press, 2012.

SCHOULTZ, L. Estados Unidos: poder e submissão. Uma história da política norte-americana em relação à América Latina. Bauru, SP: Edusc, 2000.

SILVA, Julio Cesar dos Santos. A Construção do Pan-Americanismo na Revista em Guarda: o Olhar Americano pela Defesa das Américas (1941-1946). Dissertação de mestrado. Faculdade de Ciências e Letras de Assis - UNESP, 2009.

TOTA, Antonio Pedro. O amigo americano: Nelson Rockefeller e o Brasil. São Paulo: Companhia das Letras, 2014.

O Imperialismo sedutor: a americanização do Brasil na Segunda Guerra. São Paulo: Companhia das Letras, 2000. 